\title{
Alan Rodgman, M.A., Ph.D., Recipient of the 2003 Tobacco Science Research Conference Lifetime Achievement Award
}

For here we are not afraid to follow truth wherever it may lead, nor to tolerate any error so long as reason is left free to combat it. - Thomas Jefferson, 1820

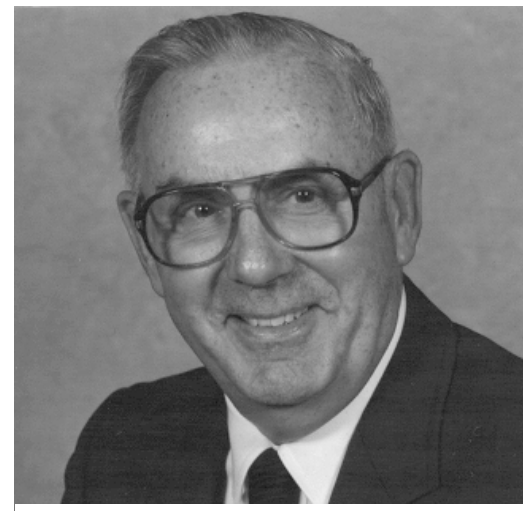

The words penned long ago by Mr. Jefferson epitomize the life and professional career of Alan Rodgman. For over a half century Dr. Rodgman has been at the forefront of tobacco science. His increasingly rare combination of keen scientific intellect, unceasing productivity, sense of tobacco science history, and unfailing attention to clear, concise, timely communication make him an ideal recipient of TSRC's Lifetime Achievement Award. Not only has Alan Rodgman made his own prodigious, personal scientific contributions to tobacco and smoke chemistry and their related toxicology, but his mentoring of associates and many other tobacco scientists has allowed him to amplify his contributions far beyond those capable of any one man. Dr. Rodgman's professional "family tree" reads as a "Who's Who" in tobacco science.

In 1945, Alan Rodgman entered the University of Toronto on two mathematics, physics, and chemistry scholarships awarded in 1942. The period between earning the scholarships and their implementation was spent on active duty in the Royal Canadian Navy during WW2. His bachelor's thesis on $N$-nitrosamines (1949), master's thesis on kinetics of a Diels-Alder reaction (1951), and doctoral thesis on oxymercuration-deoxymercuration (1953) were conducted with Dr. George $F^{1}$ Wright as his advisor. His master's and doctoral research formed part of eleven publications coauthored with Dr. Wright who, by the way, from 1954 to 1959, preceded Dr. Dietrich Hoffmann as Dr. Ernst L. Wynder's tobacco smoke chemistry colleague.

While pursuing his chemistry degrees, Rodgman conducted carcinogenesis and anticarcinogenesis research from 1947 to 1953 during summers, winter evenings, and weekends with Dr. Wilbur R. Franks, Cancer Research Professor,

\footnotetext{
${ }^{1}$ The lack of a period after Dr. Wright's middle initial is not a typographical error.
}

Banting and Best Department of Medical Research. He conducted such research full-time to mid-1954 after receiving his doctorate in 1953. Rodgman's first three scientific publications (in carcinogenesis) in 1947 and 1948 preceded the receipt of his bachelor's degree in chemistry in 1949. From 1951 to mid-1954 he also taught organic and physical chemistry plus mathematics in evening courses sponsored by the Chemical Institute of Canada.

In mid-1954, Rodgman joined the R.J. Reynolds Tobacco Company Research Department. There, he initiated its program on cigarette smoke, personally conducting the research until 1967 and actively directing it thereafter until 1987. Following successive promotions from senior research chemist to section head to division manager, he became director of research in 1976, and after an R\&D reorganization in 1980, he was appointed director of fundamental research. Rodgman became an American citizen in 1961.

Rodgman served on the Editorial Board of Tobacco Science as member and Vice-Chairman (1963-1967); on the Editorial Board of Beiträge zur Tabakforschung International (1976-1987); on the Industry Technical Committee, Council for Tobacco Research (1955-1960); on the Cooperation Center for Scientific Research Relative to Tobacco (CORESTA) Scientific Commission (1982-1985); and on several U.S government committees, e.g., the Tobacco Working Group of the National Cancer Institute's Smoking and Health Program on the Less Hazardous Cigarette (1976-1977); the U.S. Technical Study Group of the Cigarette Safety Act of 1984 (1984-1987). From 1960 to 1987 , Rodgman served on numerous Tobacco Chemists' Research Conference (TCRC) committees. In 1972, he was involved in various aspects of the joint CORESTA/TCRC Conference in Williamsburg, VA. In 1976, he persuaded his Company's management to continue its CORESTA membership. In the early 1980s, when a host site for the 1982 CORESTA Symposium did not materialize, Rodgman was instrumental in arranging for his Company to sponsor the Symposium in Winston-Salem, NC. He served as its Vice Chairman.

Alan Rodgman was the chairman for the $1984,38^{\text {th }}$ TCRC symposium entitled "Design of Low-'Tar' Cigarettes". On the occasion of TCRC's 50 $0^{\text {th }}$ Conference in 1996 he coauthored a comprehensive review and presentation entitled “The Tobacco Chemists' Research Conference: A Half 
Century Forum for Advances in Analytical Methodology of Tobacco and Its Products". The following year at the $51^{\text {st }}$ Conference, he prepared a symposium paper and presentation on "FTC 'Tar' and Nicotine in Cigarette Mainstream Smoke: A Retrospective". In addition, Dr. Rodgman has presented ten other original research papers at the conference.

In the journal Tobacco Science, he has published thirteen scientific papers. Additionally, the 1986 volume of Tobacco Science was dedicated to Dr. Rodgman to honor his prolific career.

Since retirement, he has been involved in consulting activities on the scientific aspects of litigation against R.J. Reynolds Tobacco Company. Additionally, he is a major contributor to the scientific content of Beiträge zur Tabakforschung International both through submitted papers and as a volunteer member of the editorial board. Many of these latter contributions are a consequence of the "Master Settlement" between the states and tobacco companies. Dr. Rodgman has mined the wealth of documents previously considered proprietary to clarify the intent and content of tobacco and smoke research conducted by himself, his colleagues, and other scientists. Among the papers published thus far are the following:

- "Smoke pH": A review. Beitr. Tabakforsch. Int. 19 (2000) 229-235.

- Studies of polycyclic aromatic hydrocarbons in cigarette mainstream smoke: identification, tobacco precursors, control of levels: A review. Beitr. Tabakforsch. Int. 19 (2001) 361-379.

- Some studies of the effects of additives on cigarette mainstream smoke properties. I. Flavorants. Beitr. Tabakforsch. Int. 20 (2002) 83-103.

- Some studies of the effects of additives on cigarette mainstream smoke properties. II. Casing materials and humectants. Beitr. Tabakforsch. Int. 20 (2002) 279-299.

- The composition of cigarette smoke: Problems with lists of tumorigens. Beitr. Tabakforsch. Int. 20 (2003) 402-437.
- Toxic chemicals in cigarette mainstream smoke Hazard and hoopla. Beitr. Tabakforsch. Int. 20 (2003) 481-545.

- Some studies of the effects of additives on cigarette mainstream smoke properties. III. Ingredients reportedly used in various commercial cigarette products in the USA and elsewhere. Beitr. Tabakforsch. Int. 21 (2004) 47-104.

At the 2002 CORESTA Congress held in New Orleans, Dr. Rodgman co-authored an invited speaker symposium paper entitled "Toxic Chemicals in Cigarette Mainstream Smoke - Hazard or Hoopla". In this paper the authors critically examined the proper listing and prioritizing of toxic chemicals in cigarette mainstream smoke. Moreover, the authors pointed to a number of disconcerting chemical and biological limitations in existing knowledge which calls into question the veracity of such listing strategies for their oft-stated purposes. This example is included because of Alan Rodgman's lifelong pursuit of the truth, i.e., see the cited quotation from Mr. Jefferson.

In summary, there is no question that Alan Rodgman has dedicated his professional life to the achievement of the highest standards for tobacco science. Even with this review, it is impossible to convey to an outsider the tremendous impact that this person has made to our knowledge of tobacco and its smoke. Although his own personal scientific accomplishments are by themselves worthy of public recognition, the amplification of his life's work through influence on many other tobacco scientists is difficult to quantify. Beyond his many professional achievements is a man who is widely respected and personally liked both within and outside the tobacco science community.

\section{Charles R. Green}

Winston Salem, NC, USA 